\section{La forma de las actividades}

humanas en el espacio: hacia un análisis espacio-temporal en la arquitectura

\section{| ABSTRACT}

Computational spatial analyses play an important role in architectural design processes, providing feedback about spatial configurations that may inform design decisions. Current spatial analyses convey geometrical aspects of space, but aspects such as space use are not encompassed within the analyses, although they are fundamental for architectural programming. Through this study, we initiate the discussion of including human activity as an input that will change the focus of current computational spatial analyses toward a detailed understanding of activity patterns in space and time. We envision that the emergent insights will serve as guidelines for future evaluation of design intents motivated by spatial occupancy, since we -designers- mentally constructing a model of the situation and activities on it (Eastman, 200I).

\section{| RESUMEN |}

Los análisis espaciales computacionales juegan

un papel importante en los procesos de

diseño arquitectónico, proporcionando una retroalimentación sobre las configuraciones espaciales que pueden apoyar las decisiones de diseño. Actualmente se analizan aspectos geométricos del espacio, pero aspectos como el uso del espacio no se incluyen dentro del análisis, a pesar de que son fundamentales para la programación arquitectónica. A través de este estudio iniciamos la discusión sobre la inclusión de las actividades humanas como un elemento que re-direccionará el enfoque de los análisis computacionales actuales hacia un entendimiento detallado de los patrones de actividad en el espacio y el tiempo. Tenemos la visión de que las ideas emergentes servirán como directrices para la evaluación futura de las intenciones de diseño motivados por la ocupación espacial, considerando que nosotros - diseñadoresconstruimos mentalmente un modelo de dichas situaciones y las actividades que se desarrollan en dichos espacios (Eastman, 200I).

\title{
Activity shapes: towards a spatiotemporal analysis in architecture
}

\section{INTRODUCTION}

Architects' early design decisions are essentially based on their experiences and observations of two main aspects of architectural spaces: Spatial configurations and human behavior (Gibson, 1977). Both areas converge when the focus of analysis is on the space in relation to human behavior. In this article we will overview both areas, proposing new methods for their convergence -in spatiotemporal terms. The input for computational spatial analyses is the geometry of a space; therefore all geometrically identical spaces have equal analysis results, regardless the use, function, or activity performed within the built space. Our goal is to understand the fundamental distinctions among spaces depending on their spatiotemporal occupancy patters at human scale, in other words, on the activity associated to the geometrical configuration. This will help us to understand the importance of including time and activity variables into spatial analyses. The purpose of this research is to explore and study spatiotemporal occupancy of a space, by adopting and developing methods for the emergent analyses according to the exploration prospects. Through this article we present a pilot study to test spatiotemporal analyses of activity shapes, the most abstract representations of spatial occupancy data. The analyses lead us to a better understanding of how humans occupy space in terms of dispersion and gravitation, inherent properties of spatial arrangements in statistical terms.

\section{EXISTING MODELS FOR SPATIAL ANALYSIS}

Spatial configurations have been largely studied in architecture, usually utilizing computational methods for spatial analyses at building or urban scales. However, they have been analyzed geometrically and geometrically derived exclusively. Various models for spatial analysis were developed. Hillier and Hanson (1984) developed Space Syntax theory, creating diverse representations of the components of the space and their relationships. The most common representation is Axial Map, which represent the space connections as a set of straight and longest lines. From the set of lines, they extracted

* College of Architecture Georgia Institute of Technology Hinman Research Building 723 Cherry Street, Lab 234 Atlanta, GA 30332, USA paulagomez@gatech.edu

** School of Industrial Design \& School of Interactive Computing College of Architecture \& College of Computing Georgia Institute of Technology Health Systems Institute, $210 B$ Atlanta, GA 30332, USA.

*** School of Computer Science and Communication Royal Institute of Technology SE 10044 Stockhol. 
a graph representation of spatial connections, calculating how integrated the space was, by calculating how connected "each line was with respect to all other lines in the graph» (Hillier \& Hanson, 1984). Also, several computer applications have been developed through the years while the area of spatial analysis was developing. Some of them are Spatialist (Peponis et al., 1998), SpaceBox (Dalton, 1988b), Omnivista (Conroy Dalton \& Dalton, 2001), and UCL Depthmap, developed by Turner at $U C L$ in 1998, is the most well known tool within the area of spatial analysis in architecture. It is primarily «a computer program to perform visibility analysis of architectural and urban systems». It takes as an input the geometric layout of a building or urban design, and as a result it constructs a heating map of «visually integrated» zones intended as to measure the space in terms of visual fields (Turner, A., 2004). UCL Depthmap creates Visibility Graph Analysis; Axial networks for Axial Map analysis, and Agent Analysis, by importing as an input the space geometrical attributes, with the main purpose of studying the correlation of social practices in spatial settings. Although geometry is a fundamental aspect for the interpretation of spatial occupancy, it is definitely not the only one. Agent Analysis includes other parameters such as a set of algorithms for occupancy toward specific goals, which certainly is not an exclusive motivation for humans.

Several spatial analyses methods derived from geometrical properties of a space have been developed: Isovists, developed by Benedikt (1979) attempts to measure human experience in relation to the geometry of a space. He associates the space configuration to the visual experience obtaining «lsovists» or polygons that represent the visual field of a habitant from a specific position in space. Isovists' intensities were studied by Do and Gross (1997), who proposed a set of methods to support architectural design in terms of gradients of spatial perception. Key (2010) studied computable spatial qualities, such as Complexity and Spaciousness, based on geometrical features of Isovists. And Koile (1997) proposed model representations of the space in terms of circulation, links, space use, and connectivity, all derivable from spatial geometrical properties. All these approaches address space as «the void that is inside the geometric representation» (Bafna, 2003), and the relationships among computable objects, such as doors, corridors, and spaces. The resulting values of integration, connectivity, or depth (described by Hillier \& Hanson, 1984), are interpreted as how the space is «occupiable» -or potentially occupied (Turner, 2004)- to then correlate them with social behavior. However, these results only depend on the geometrical attributes of the space, but not on other attributes such as the architectural program. In other words, if two identical layouts with two different architectural programs are evaluated using traditional spatial analysis, the output will be identical for both spaces.

In this scenario, one research question emerges: "How can nominal-spatial analyses methods be augmented to support behavior-analyses toward an integrated architectural analysis?». In 2007, Markhede and Miranda intended to answer a similar question by observing the how space syntax tools have disregarded the occupied space by giving priority to the potentially occupied space, or «occupiable space» (Turner, 2004). Markhede and Miranda measured integration aspect of a space from an occupancy perspective by developing SPOT Spatial Positioning Analysis tool, which examines the relationships between occupied spaces, offering "a new insight into how we approach space syntax» (Dursun, 2007). Our research intends new insights to spatial analysis from a computing approach, proposing a semiautomatic analysis of occupancy, space, and time, focusing on the parameters of occupancy that may characterize spatiotemporal analyses.

\section{BEHAVIOR ANALYSIS}

In the area of human behavior, numerous researches have focused on tracking external causes and effects of behavior. They utilize methods for data collection that range from low to high resolution. Commonly, data is collected manually by pen-and-paper direct observation method (Barely, 1990), focusing on particular characteristics of human behavior such as position, posture, and frequency of movements among others (Bechtel 1997, Peponis et al., 2004; Rashid et al., 2006). From a computing perspective, the accuracy of the data-capture increases. Important amount of work is on the development of several tools that have been designed to automatically capture human movements in space, using video cameras or sensors (Romero, 2008). Most of them, however, focus on the data and visualization. However, users that would like to perform quantitative analyses would have to export the data to external tools, allowing to perform classic analyses.

On the one hand, pen-and-paper direct observation methods are the most widely used for data collection of human behavior such as movement, occupancy, and interaction among persons. However, as this process requires annotation, coding, mapping, and transfer, it «provides low-resolution data and allows only conceptual replication of the method» (Gómez, Romero \& Do, 2012). Several studies have been based on this method to collect data in different building types and layout shapes, which has allowed researchers to answer some general questions based on the resolution of the data obtained. Some well known examples are studies in museums, correlating movements with visual fields (Bafna, 2003); and in offices, which with its re-configurable layout influences the outputs, correlating movement, visual fields, and individual's interaction (Choi, 1999). From these studies, researches have demonstrated strong correlation of building layouts and general human occupancy, movements and interaction among them.

On the other hand, from the Computer Science area, smart tracking systems for data collection, which includes wearable sensors, radio frequency identification tracking system (RFID), Global positioning systems, cameras, and hybrid systems, are less time consuming, semi-automatic, provides higher-resolution of spatial and temporal data, and allows literal replication (Liu, Darabi, Banerjee \& Liu, 
1. Sequence of frames captured from one of the video camera on the ceiling: game scenario.

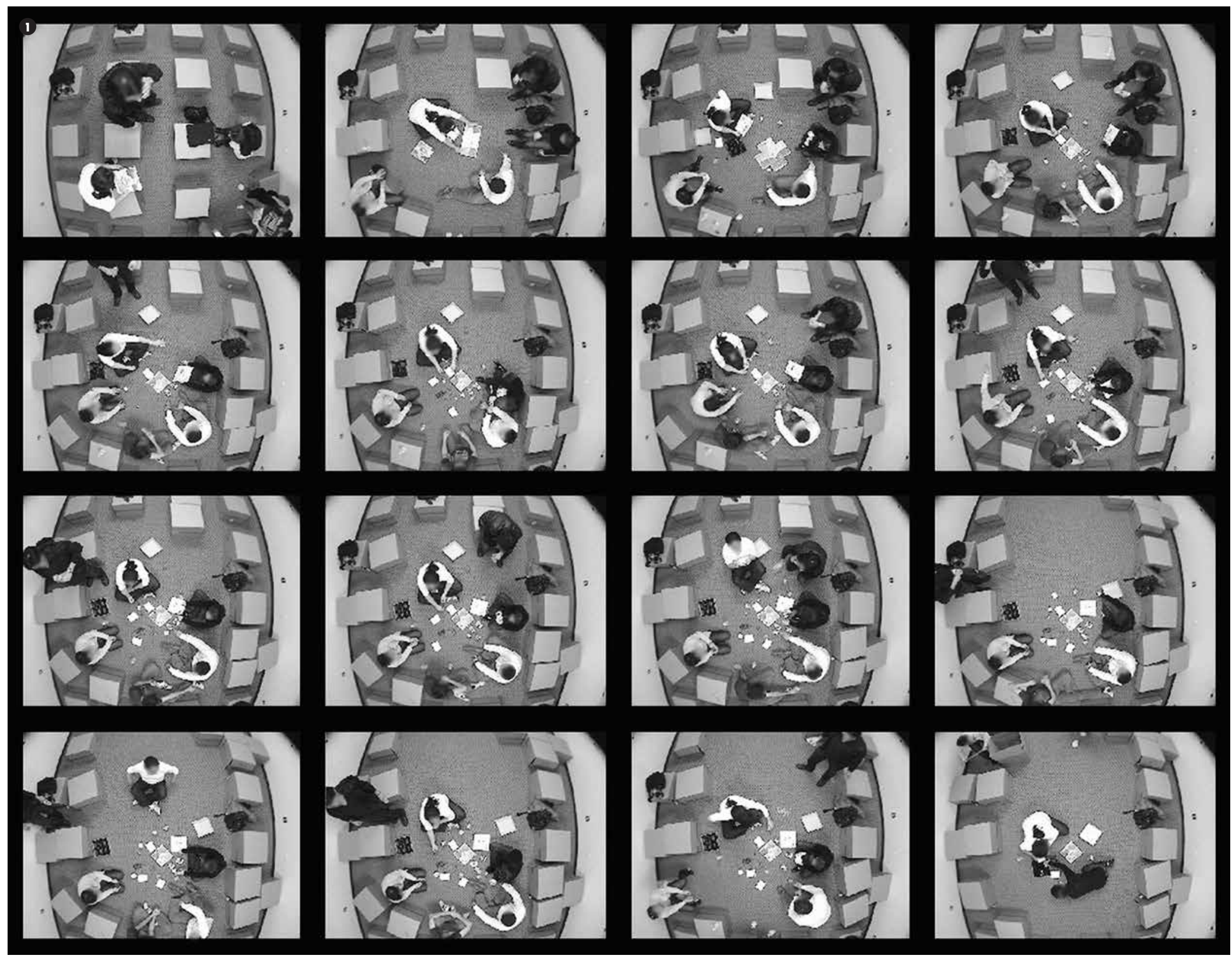

2007). We decided to adopt a method for data collection that allows us to obtain finer grain data. In our study, we seek to answer more fine grain questions, such as what are the detailed patterns of human activities? What are the spatial patterns as well as the temporal patterns of what we have called «Activity Shapes»? What are the spatiotemporal patterns by human postures, within the «Activity Shapes»? Our intention is to find some pattern underlying structures that characterize human activity, focusing on the distribution of people and their postures -standing, sitting, and walking-in space and over time. To accomplish that goal, a higher-resolution data collection method is needed.
SPATIOTEMPORAL ANALYSIS IN ARCHITECTURAL DESIGN

For our exploratory study, we decided to use an intermediate method for data collection: Video capture. We designed an experiment inside the "Child Study Laboratory» in Health System Institute facilities at Georgia Tech. The 
2. A top-perspective-view of the Game Activity Cube.

3. A top view of Game activity shape, and its spread over time (to the right).

space is a small room designed for the study of autism in children. To capture children's behavior, the room is equipped with 11 cameras embedded in the walls (8) and the ceiling (3). A computer system supports the capture of all videos collected. For our experiment, we will use the 3 cameras in the ceiling, so we can more easily map the position of individuals to the floor layout.

Based on Gans' statement that people tend to behave socially depending mainly on three factors: Space, situation, and culture (Gans, 1967; Sommer, 1969; Hall, 1966), we designed an experiment that maintains fixed space and culture, and modifies the second variable: Situation. Our exploratory study consists on maintaining invariable the space layout, its neutral furniture configuration, and the participants, isolating the activity to be performed, which impact the situation to which participants are exposed. We selected the different activities to impact the situation: Watching television, taking a coffee break, and playing a board game. They last 20 minutes each, and were chosen under the hypothesis that the interaction among people vary from one to another, impacting the positions and postures they will take in space.

\section{METHODS}

We recorded human activities through overhead video cameras obtaining high resolution of individual's position in space. To start, we explored the data without a predefined statement, using the Exploratory Data Analysis (EDA) approach, to discover the most identifiable characteristics of spatial occupancy. For this purpose, we generated visualization of the occupancy of the space in the aggregation of individuals' positions in space and over time. We named it «Activity shapes» due to the strong influence of the activity on the resulting representation (Gómez, Romero \& Do, 2012). Afterwards, we observed the videos and meticulously annotated individual's positions at one-second intervals. From these observations, we obtained a dataset containing four variables:
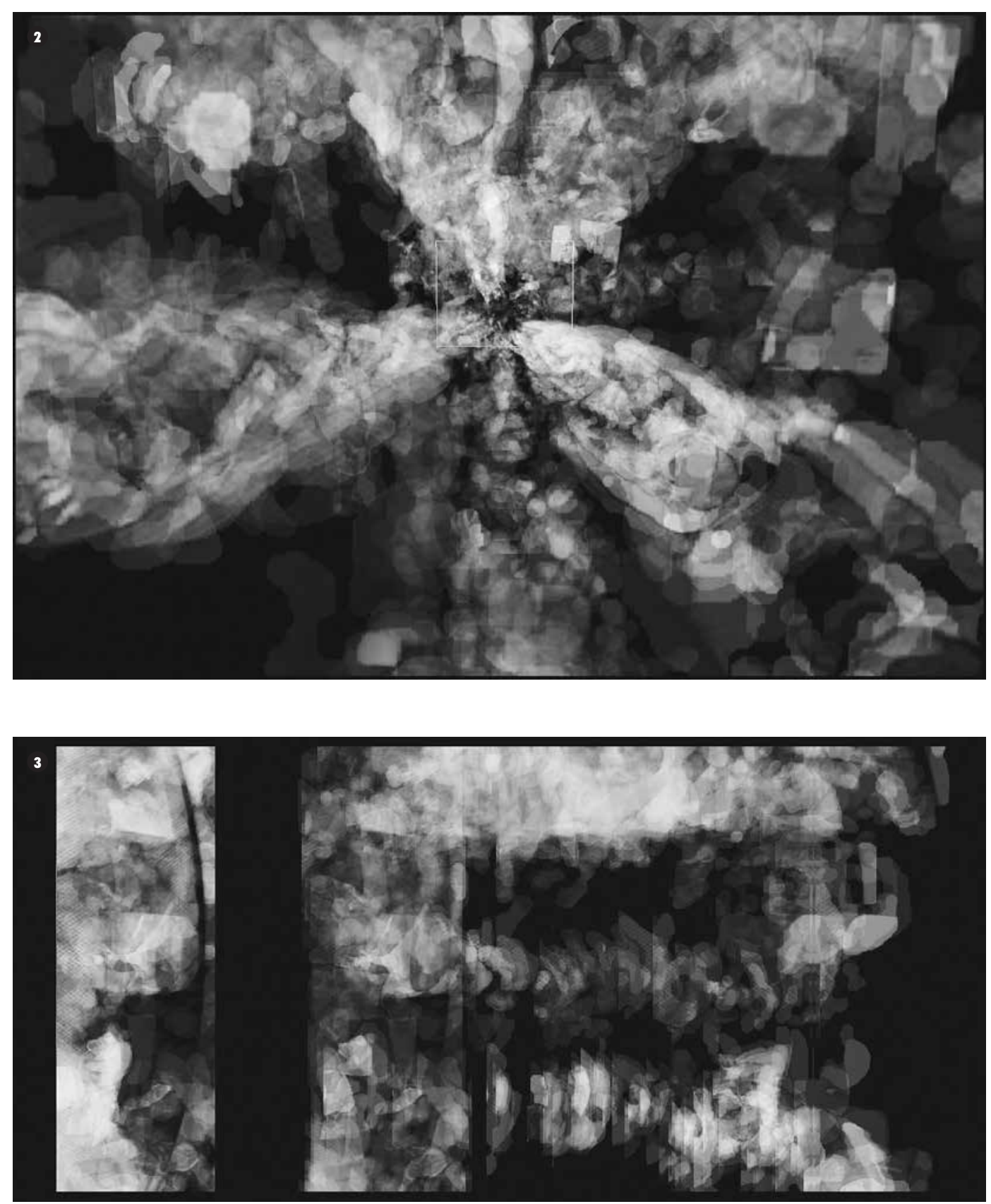

individual's identification (ID), individual's position $(x, y)$, posture $(s, t, w)$ and time in seconds ( $t$ ). Finally, we described a computable method for automatic data analysis.

For our analyses we integrated automatic methods for visualization with observation of videos. Our main goal is to develop methods for analysis of spatiotemporal human behavior patterns. To create the visualization presented in the FIgUre 2, we utilized Viz-A-Vis, a tool developed by Romero (Romero et al., 2008) that records and processes human movements from overhead videos (FIGURE 2). It automatically 
4. A: Perspective of the activity cube for the game scenario.

B: Two perspectives of the activity cube for the game scenario, and a section of activity shape in space.

5. A: Game scenario top view.

B: Game scenario occupancy second 1140 .

C: Aggregated activity shape of game scenario.

D: Activity shapes of game scenario by postures.
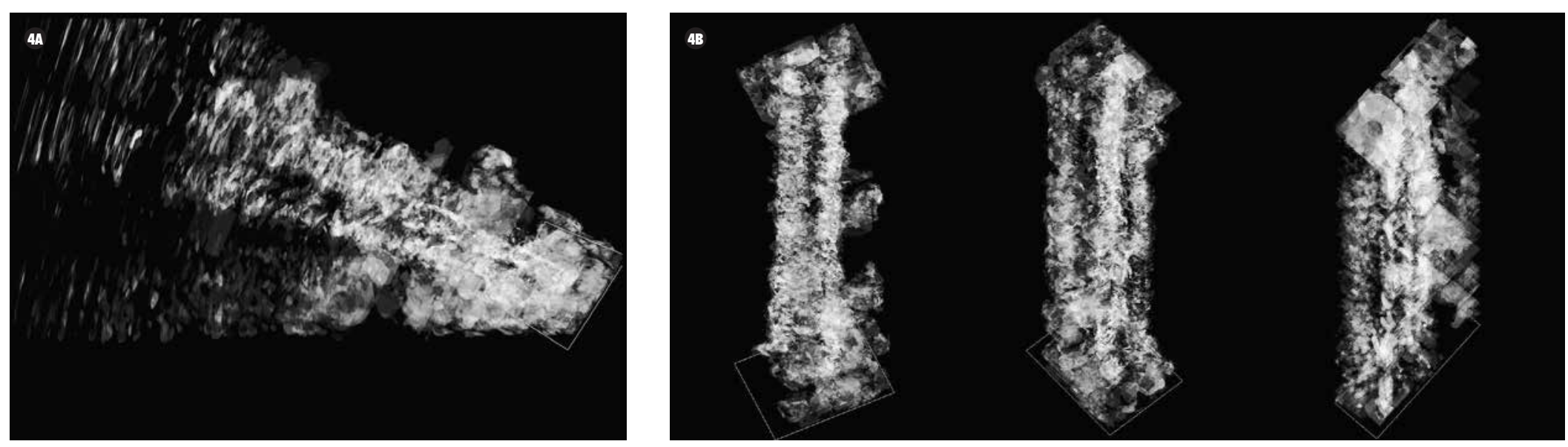

constructs the «Activity map» by aggregating images of people's movements (FIGURE 3). It also displays a three-dimensional visualization in SketchUp, the 3D «Activity cube» (FIGURE 4A AND 4B).

Observing the videos, we obtained the activity shapes of the three scenarios by constructing a visual representation that indicates the amount of time each participant spent in a specific location and posture in space. To identify a specific location over the floor layout, we divided the space into a grid of 9 by 13 cells. The size of each cell in the grid is $0.45 \mathrm{mt}$., a person's intimate space defined by Hall (Hall, 1966). We assigned $x$ and $y$ coordinates to identify each individual's position in space, calculate distances among them, and calculate centroids of their positions. Later, we analyzed and compared the activity shapes of the three different activity sessions, expecting to find different occupancy dispersion in space, to answer the following research questions: (1) How uniform was the distribution of people in the space during the activity session?, and (2) How clustered was this distribution?

\section{DESCRIPTIVE METHODS AND ANALYTICAL TOOLS}

We rationalized the information from the activity cube, and constructed an aggregated Activity Shape by posture, as indicated in the FIGURE $5 \mathrm{~A}, 5 \mathrm{~B}, 5 \mathrm{C}$, AND 5D. First, we associate the information to a position in space and assign it to a cell. Then, we aggregate the occupied cells, to then filter them by posture: Sitting (s), standing $(t)$, and walking $(w)$.

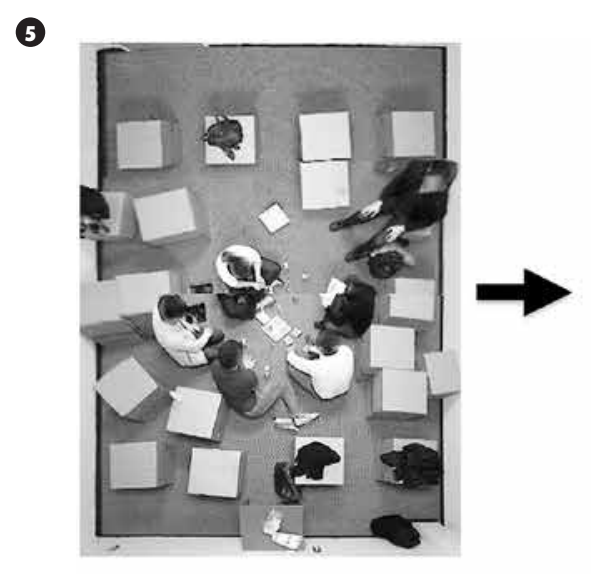

(A)

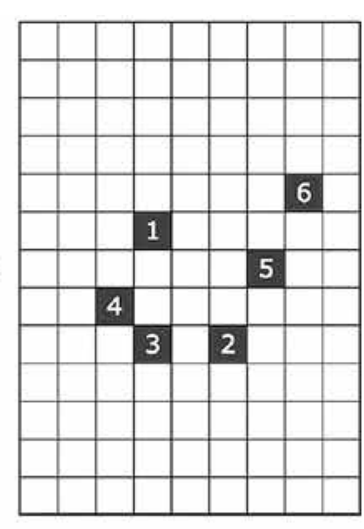

(B)
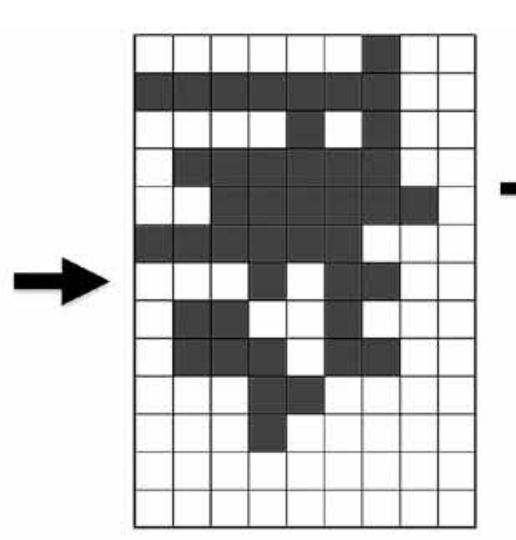

(C)

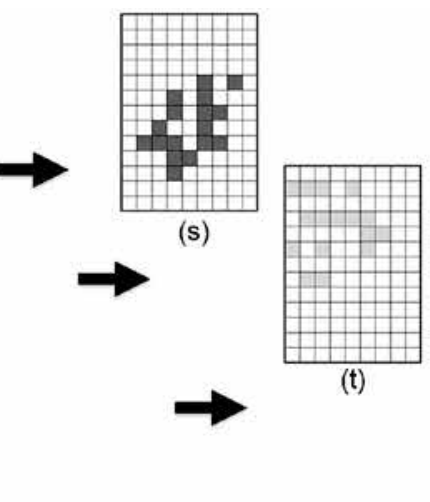

(D)

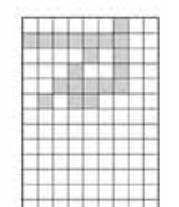

(w) 
Each cell has $\mathrm{x}$ and $\mathrm{y}$ coordinates, and values of 1 or 0 by second, indicating if the cell was occupied or not respectively. Additionally, the attribute of posture indicates if the cell was occupied by sitting on it, standing on it, or walking by it. The data we utilized for the spatiotemporal analysis is occupancy/second.

\section{ANALYSES METHODS}

Previously, we introduced the concept of "Activity shapes, which help us to obtain distinctive analyses of activities in aggregated and spatiotemporal terms» (Gómez, Romero \& Do, 2012). In this research, used Viz-A-Vis, a visualization tool that helps us to characterize the features of the activities, which computes motion by adjacency frame difference (Romero et al., 2008). Resulting frames are vertically stacked, creating 3D activity cubes (FIGURE 4A AND 4B). All the quantitative analytical methods are based on the representation of the activity space as an array of spatial units. Each cell has three values, $x, y$ and a binary value of 1 or 0 , indicating if the cell is occupied or not, filtering them by posture (FIGURE 5). We structured the analysis in two main categories: Aggregated and Spatiotemporal analyses. Aggregated analysis focuses on the geometry and the topology of the accumulative activity shape over time, and spatiotemporal analysis focuses on the changes in the activity attributes over time (Gómez et al., 2012).

TABle 1

Methods, analysis types, and their descriptions

\begin{tabular}{l|l|l|l}
\hline Method & Analysis type & Description & References \\
\hline Spatiotemporal & Dispersion & Percentage of occupancy of cells over time & Physics \\
& Gravitation & Distances from each participants to one specific pivot point & Statistics \\
\hline
\end{tabular}

In the context of the aggregated analysis, we developed four geometrical calculations -perimeter, area of occupancy, bounding area of occupancy, and activity density- and four topological measures: clusters, cluster density, holes, and adjacent edges. Aggregated analyses are not the focus of this article, but Spatiotemporal analyses by posture.

\section{Spatiotemporal Analyses}

The aim of proposing spatiotemporal analysis in architecture is to materialize the well-known design intent that consists on simulating human behavior in our minds when we, architects, define layout configurations. This paper focuses on spatiotemporal analyses since they consider variables of individuals (i) or time (t). We analyzed the occupancy and postures $(s, t, w)$ in space for each activity by evaluating the changes of dispersion and gravitation of individual's positions over time.

\section{a. Dispersion}

We call dispersion to the percentage of time a cell is occupied during the session. For a visualization of results, the transparency of the color indicated the percentage a cell was occupied. The darker the color, the higher the percentage that specific cell was occupied during a session. If the cell is white, it was never occupied during that session.

\section{b. Gravitation}

We call gravitation to the distribution of distances from each participant to a pivot point every second in time. We calculated individual and total gravitation to four pivot points: Focus of the activity (i.e., TV, coffee machine, game board) (see figure in television scenario), Center of the room (see figure in coffee break scenario), and Center of gravity of the activity (see figure in game scenario). We calculated the average

TABLE 2

Summary of dispersion in the three scenarios by postures

\begin{tabular}{|c|c|c|c|c|c|c|c|c|c|c|c|c|}
\hline \multirow[t]{2}{*}{ Spatiotemporal } & \multicolumn{4}{|c|}{ TV } & \multicolumn{4}{|c|}{ Coffee } & \multicolumn{4}{|c|}{ Game } \\
\hline & $S$ & $\mathrm{~T}$ & W & A.S. & $S$ & $\mathrm{~T}$ & W & A.S. & $S$ & $\mathrm{~T}$ & W & A.S. \\
\hline$>80 \%$ & 5 & 0 & 0 & 5 & 0 & 0 & 0 & 0 & 15 & 1 & 0 & 16 \\
\hline $80 \%-50 \%$ & 0 & 0 & 0 & 1 & 3 & 1 & 0 & 3 & 2 & 6 & 0 & 6 \\
\hline$<50 \%$ & 4 & 5 & 0 & 6 & 9 & 38 & 41 & 57 & 0 & 9 & 20 & 20 \\
\hline Total $\mathrm{N}$ of cells & & & & 116 & & & & 116 & & & & 116 \\
\hline Occupied area & 9 & 5 & 0 & 12 & 12 & 39 & 41 & 61 & 17 & 16 & 20 & 42 \\
\hline
\end{tabular}


Euclidean distance between the pivot point and each individual. TABLE 3 present the average distances in each scenario.

Significant differences of Activity Shapes in the comparison of the three scenarios can be corroborated in the gravitation analysis. For example, the first measure that describe the differences among scenarios is the distance to the foci. In the first two scenarios, television and coffee break, a similar distant interaction with the foci is described with measures of aproximately 8 cells. However, a significant difference in this measure is presented in the game scenario, since this activity requires physical interaction with the board game.

Regarding the distances from each individual to the geometric center of the room, television and coffee break scenario are similar. The difference with the result in the game scenario is due to the action of the participants when moving the board game, which was located in the focus at the beginning of the session, to the center of the room.

When we cross compared the three scenarios using the gravitational measurements, we found high statistical differences $(<0.0001 \mathrm{p}$-value $)$ among the activities performed in the exact same spatial layout. With these values, we could demonstrate that the layout has not caused the differences of spatiotemporal activity shapes.
6. Dispersion matrix of postures vs.occupancy data for the Game scenario. They describe the criteria of percentage of time a cell is occupied. Purple indicates sitting (s), Green indicated standing ( $t$ ), and Cian indicates walking (w). Darker color indicates that a cell was occupied during at least $80 \%$ of the time; Medium indicates between $80 \%$ and $50 \%$; and light colors less than $50 \%$ of the time.

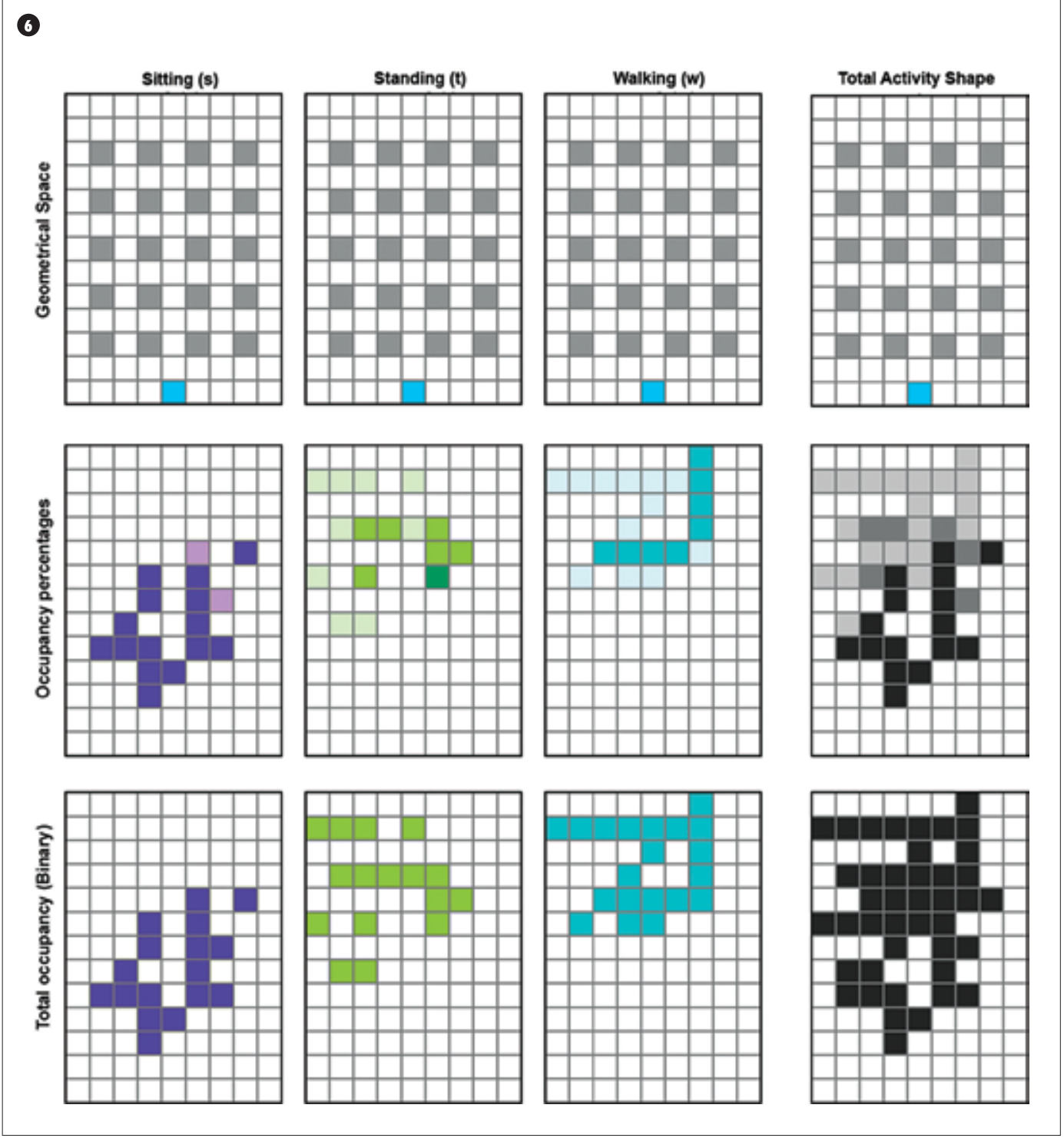

TABLE 3

Summary of the average distances expressed in a «cell» unit. Adapted from Activity shapes (2012)

\begin{tabular}{lccc} 
Scenario & Dist to foci & Dist to geometric center & Dist to centroid \\
\hline TV & 8.01 & 3.04 & 0.65 \\
\hline Coffee & 8.26 & 3.57 & 1.75 \\
\hline Game & 1.75 & 1.32 & 4.37
\end{tabular}


7. Dispersion and Gravitation matrix of postures $(s, t, w)$ vs. occupancy data for all scenarios. Dispersion, represented by transparency, indicates the percentage of time a cell was occupied. Gravitation describes the distances from specific pivot points: Foci (television, cian), Geometric center of the room (Coffee break, purple), and Occupancy centroid (Game, green)

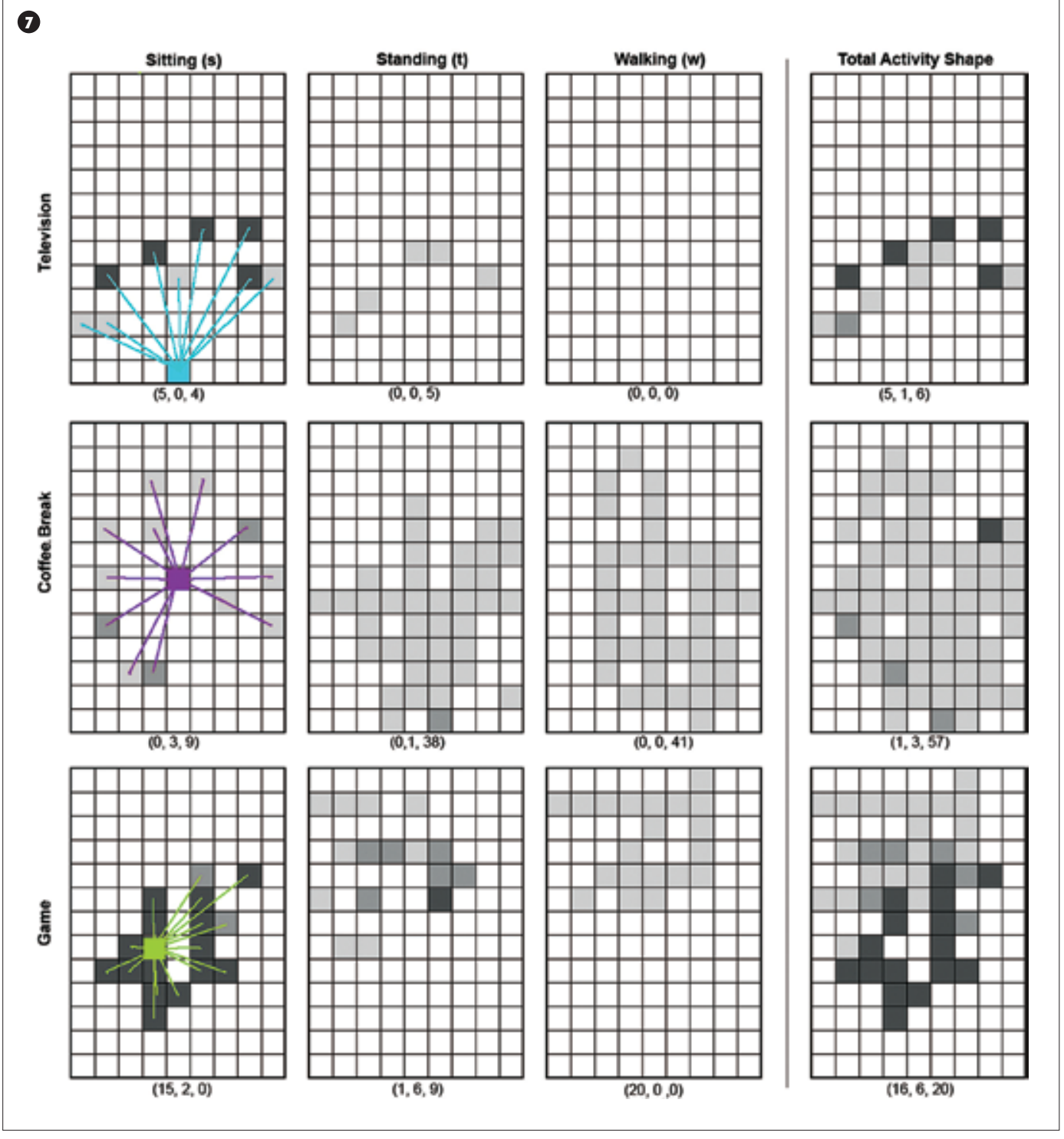

\section{DISCUSSION}

The main focus of this article was to present an informal description of the results obtained from our analyses of the activity shapes. In the spatiotemporal analyses of Activity Shapes - dispersion and gravitation- we found that the concentric activity - playing a board game- is the most different of the three activities. In terms of dispersion it has the highest weighted occupancy (percentage of time a cell is occupied) of participants around a foci. In the three scenarios, participants distribute around the foci with different distances, being the minor distance the Game scenario followed by the coffee scenario, and last the TV scenario.

These descriptions are supported with the gravitation analysis -measurement of distances between the center of the room, the foci, and the activity centroid. The highest total distance between individuals was found on the TV session -corroborating the lack of clusters formation between participants observable in the visualization generated by the Viz-a-vis toolfollowed by the game scenario, in which the clustering was stable. The lower total distance between individuals was found in the coffee scenario, confirming the variety of clustering formations along the timeline.

The use of statistical analysis facilitates our understanding of the patterns of spatial behavior independently from the layout configuration and correlated to the activity performed. The statistical results of this study showed significant differences among three scenarios that were not necessarily influenced by the layout. This make our study pioneer in analyzing activities in relation to situational factors, without attempting to explain the influence of the layout configuration on the activity. In future studies, we plan to demonstrate that a scheduled activity will occur independently to the spatial configuration, however, the shape that the activity will take will be modified by the nature of the activity.

As the fundamental direction in this research area, the long-term goal is to include human activity as essential input into spatial analysis, which is traditionally based on the layout geometrical configuration. A long-term contribution is to include an exploratory design environment that, through collaborative efforts, can be used towards constructing an actual database of spatiotemporal activity from postoccupancy evaluations. The goal is to render spatial evaluations in early stages of design, using information of human behavior that is usually implicit in architect's evaluation of early design decisions. This information will enable designers to explore ideas and test scenarios about spatial configurations and spatial occupancy, to focus on answer questions such as «How to analyze a spatial configuration for a specific activity setting?».

\section{ACKNOWLEDGMENTS}

We thank to the Child Study Laboratory for their facilities and the video capture infrastructure, 
as well as the participants for their willingness during the experiment sessions. We thank John Peponis for his feedback in this research. The first author thanks Fulbright-CONICYT Chile for sponsoring the first years of her doctoral studies.

\section{REFERENCES}

Bafna, S. (2003). «Space syntax: A brief Introduction to Its Logic and Analytical Techniques». Environment and Behavior, Vol. $35 \mathrm{~N}^{\circ}$ 1. 17-29.

Barley, S. R. (1990). «lmages of Imaging: Notes on Doing Longitudinal Field Work». Organization Science. Special Issue: Longitudinal Field Research Methods for Studying Processes of Organizational Change 1 (3): 220-247.

Bechtel, R. B. (1997). Environment and Behavior: An Introduction, Sage Publications, Inc.

Benedikt M. L. (1979). To take hold of space: isovists and isovist fields, Environment and Planning B 47-65.

Choi, Y. K. (1999). «The morphology of exploration and encounter in museum layouts'». Environment and Planning B: Planning and Design (26) pages 241-250.

Churchill, W. (1943). «We shape our buildings, and afterwards our buildings shape us...». House of Commons. Meeting in the House of Lords. 28 Oct. 1943

Conroy Dalton, R., Dalton, N. (2001). «Omnivista: An application for isovist field and path analysis». In: Peponis et al. (2001), pp. 25.1-25.10.

Conroy, D. R. (2003). "The secret is to follow your nose." Environment and Behavior 35, pages 107-131.

Cosco N., Moore R., and Islam M. (2010). «Behavior mapping: A method for linking preschool physical activity and outdoor design». Medicine \& Science in Sports \& Exercise, 42(3), 513-519.

Dalton, N. (1988b). SpaceBox. UCL, London.

Do, E. Y. L. and Gross, M. D. (1997). «Tools for visual and spatial analysis of CAD models». Computer Assisted Architectural Design Futures 97.
Dursun, P. (2007). Space Syntax in Architectural Design. In A. S. Kubat, O. Ertekin, Y. I. Guney \& E. Eyuboglu (Eds.), Proceedings of $6^{\text {th }}$ International Space Syntax Symposium (pp. 056-001 - 056012). Istanbul: ITU Faculty of Architecture.

Eastman, C. (2001). New Directions in Design Cognition: Studies on Representation and Recall. In C. M. Eastman, W. M. McCracken \& W. C. Newstetter (Eds.), Design Knowing and Learning: Cognition in Design Education. (pp. 79-103). Amsterdam: Elsevier.

Gans, H. J. (Ed.) (1968). «The Potential Environment and the Effective Environment». People and Plans, NY: Basic books.

Gibson, J. (1977). «The concept of affordances». Perceiving, acting, and knowing: 67-82.

Gómez, P., Romero, M., Do, E. (2012). «Activity Shapes: Analysis Methods of Video-Recorded Human Activity in a Co-visible Space», Proceedings of $8^{\text {th }}$ Space Syntax Symposium (pp. 8196-001 - 8196-025). Chile: PUC Santiago.

Grant, L. and Evans, A. N. (1994). Principles of Behavior Analysis. New York, HarperCollins College Publishers.

Hall, E. T. (1966). «The Hidden Dimension». Garden City, NY: Doubleday.

Hillier, B. and Hanson, J. (1984). The social logic of space, Cambridge University Press Cambridge.

Key, S., Grosss, M. D., et al. (2008). "Computing Spatial Qualities For Architecture». Proceeding of ACADIA: 472-477.

Koile, K. (2004). An intelligent assistant for conceptual design.

Liu, H., Darabi, H., Baneriee, P. \& Liu, J. (2007). Survey of wireless indoor positioning techniques and systems. Systems, Man, and Cybernetics, Part C: Applications and Reviews, IEEE Transactions on, 37(6), 1067-1080.

Markhede, Henrik, and Miranda Carranza, Pablo. (2007). Spatial Positioning Tool: a prototype software and some background correlation data. Proceedings, $6^{\text {th }}$ International Space Syntax symposium, Istanbul, vol II, pp. 102.1- 102.11.

O'Sullivan, D., Turner, A. (2001). Visibility graphs and landscape visibility analysis. International Journal of Geographical Information Systems 15 (3), 221-237.

Peponis, J., Wineman, J., Rashid, M., Kim, S., Bafna, S. (1998). Spatialist. Georgia Tech, Atlanta.

Peponis, J., Conroy Dalton, R., Wineman, J., and Dalton, N. (2004). «Measuring the effects of layout upon visitors' spatial behaviors in open plan exhibition settings». Environment and Planning B: Planning and Design 2004, (31) 453-473.

Rashid, M., Kampschroer, K,. Wineman, J., Zimring, C. (2006). «Spatial layout and face? to? face interaction in offices-a study of the mechanisms of spatial effects on face? to? face interaction». Environment and Planning B: Planning and Design 33(6) 825-844.

Romero, M., Summet, J., Stasko, J., and Abowd, G. (2008) «iz-A-Vis: Toward Visualizing Video through Computer Vision». IEEE Transactions on Visualization and Computer Graphics.

Shpuza E, Peponis J. (2008). «The effect of floorplate shape upon office layout integration». Environment and Planning B: Planning and Design 35(2) 318-336.

Sommer, R. (1969). «Personal Space: A Behavioral Basis for Design». Englewood Cliffs, NJ: Prentice? Hall.

Steen, J. and Markhede, H. (2010). «Spatial and Social Configurations in Offices». Journal of Space Syntax, (1) 1,121-132.

Turner, A. and Penn, A. (1999). Making isovists syntactic: isovist integration analysis, Citeseer.

Turner, A., Doxa, M., et al. (2001). «From isovists to visibility graphs: a methodology for the analysis of architectural space». ENVIRON PLANN B 28(1): 103-121.

Turner, A. (2004). «Depthmap 4, a researcher's handbook», http://www.vr.ucl.ac.uk/depthmap/ handbook/depthmap4.pdf

Van der Spek, S., Van Schaick, J., De Bois, P., and De Haan, R. (2009). «Sensing Human Activity: GPS Tracking». Sensors, 3033-3065. SSN 1424-8220.

Winograd, T. Flores, F. (1987). Understanding computers and cognition: a new foundation for design. Addison Wesley, Reading, Mass. 